\title{
Assessment of carpal tunnel syndrome via ultrasonography among hospital workers: a screening study
}

\author{
Mai Fathy * (1), Ahmed ElSadek, Eman Hamid and Amr AbdEIMoneim
}

\begin{abstract}
Background: Carpal tunnel syndrome is a reasonably common disorder among working individuals. It may also be a cause of functional impairment. The aim of the study was to screen for the presence of carpal tunnel syndrome among hospital workers by non-invasive ultrasound.

Results: The prevalence of carpal tunnel syndrome diagnosed by ultrasound among hospital workers was $21.5 \%$. Age and Boston carpal tunnel questionnaire scale were positively correlated to median nerve cross sectional area.

Conclusions: Ultrasound can be used as a non-invasive and convenient method for screening for carpal tunnel syndrome.
\end{abstract}

Keywords: Carpal tunnel syndrome, Median nerve, Occupational risks, Ultrasound, Hospital workers, Screening

\section{Background}

Carpal tunnel syndrome (CTS) is one of the most common painful and disabling conditions related to hand usage. Moreover, it is commonly a source of substantial disability [1]. It was estimated that $34 \%$ of hospital workers have CTS [2]. Ultrasonographic measurements of the median nerve cross sectional area (CSA) provides comparatively high diagnostic accuracy for CTS and can be considered as a non-invasive, alternative and complimentary diagnostic modality for the evaluation of CTS [3]. Neurophysiological studies have a false negative result with sensitivity ranging from 49 to $86 \%$. In addition, they provide no anatomical information regarding the median nerve and possible etiologic factors [4].

Accordingly median nerve assessment by ultrasound (US) is considered the chief reliable screening tool in screening for CTS [5]. US is an imaging modality that can be used as a first-line diagnostic tool for CTS due to its noninvasiveness, wide availability and accuracy [6].

\footnotetext{
*Correspondence: maifathy23@gmail.com

Neurology Department, Faculty of Medicine, Ain Shams University, Cairo, Egypt
}

Screening for CTS presumably will help to reduce the disability burden caused by CTS within the work places [1].

The aim of the study was to screen for the presence of carpal tunnel syndrome among hospital workers by noninvasive ultrasound.

\section{Methods}

This is an observational cross-sectional study. This study included 274 wrists of 137 participants working in Ain Shams University hospital. Participants were included if they were more than 18 years, working as doctors, nurses, secretaries or manual workers. Participants with history of diabetes mellitus, thyroid disorder, renal or hepatic disorders, rheumatoid arthritis, gouty arthritis, chemotherapy intake, direct trauma to upper limb, symptoms suggestive of peripheral neuropathy, or current pregnancy were excluded. All participants were subjected to clinical assessment by Arabic version of Boston carpal tunnel questionnaire (BCTQ) [7]. The BCTQ questionnaire is formed of two sections: A Symptom Severity Scale and a Functional Status Scale. The Symptom Severity Scale comprises 11 questions and 
the FSS comprises eight questions. Each question scoring ranges from one (no symptoms) to five (very severe symptoms) [7]. Median nerve area was measured using ultrasound (Esaote, my lab five, Italy). Linear 5-12 MHz probe was placed on distal wrist between pisiform bone medially and scaphoid bone laterally to provide short axis view of median nerve at its inlet to carpal tunnel. CSA of both median nerves was measured from inner border of epineurium. A CSA $>10 \mathrm{~mm}^{2}$ was considered to be diagnostic for CTS. CSA $>10 \mathrm{~mm}^{2}$ and less than $13 \mathrm{~mm}^{2}$ was considered mild, CSA $>13 \mathrm{~mm}^{2}$ and less than $15 \mathrm{~mm}^{2}$ was considered moderate. CSA $>15 \mathrm{~mm}^{2}$ was considered severe [8].

All procedures performed in the study were in accordance with the ethical standards of the faculty of medicine, Ain Shams University research and ethical committee. Written informed consent was obtained from participants for participation.

Statistical analysis: Statistical analyses were done using SPSS 25 (IBM SPSS ver. 25, NY, USA, 2017). Level of significance was defined as $p<0.05$. $T$ test was used for continuous variables (results are referred to as

Table 1 Demographics of total sample

\begin{tabular}{|c|c|c|c|c|}
\hline & & & \multicolumn{2}{|c|}{$\begin{array}{l}\text { Total subjects } \\
\text { (Number }=137 \text { ) }\end{array}$} \\
\hline & & & Number & Percent \\
\hline \multicolumn{3}{|c|}{ Age $($ mean $\pm S D) /$ median } & \multicolumn{2}{|c|}{$(40.53 \pm 11.234) / 41$} \\
\hline \multirow[t]{2}{*}{ Gender } & Male & & 35 & 25.5 \\
\hline & Female & & 102 & 74.5 \\
\hline \multirow[t]{4}{*}{ Occupation } & Medical & Physician & 20 & 14.6 \\
\hline & & Nurse & 56 & 40.9 \\
\hline & Non-medical & Secretary & 36 & 26.3 \\
\hline & & Worker & 25 & 18.2 \\
\hline
\end{tabular}

means \pm standard deviation), and Chi square test for categorical ones (results are referred to as frequency and percentage). In addition, Kruskal-Wallis as well as Mann-Whitney Test were used in subgroup analysis. Pearson correlation and linear regression were used to test correlation and prediction between related continuous variables.

\section{Results}

The mean age of participants was $40.53 \pm 11.234$ (range $=20-75)$. Among them $35(25.5 \%)$ were males, $102(74.5 \%)$ were females, $20(14.6 \%)$ were physicians, $56(40.9 \%)$ were nurses, $36(26.3 \%)$ were secretaries, $25(18.2 \%)$ were manual workers (Table 1$)$. The mean BCTQ was $19.86 \pm 3.42$ (range $=19-51$ ). The mean median nerve CSA by ultrasonography was $9.08 \pm 2.5$ $\mathrm{mm}^{2}$. Among the study population $59(21.5 \%)$ were found to have abnormal median nerve CSA, 47(79.7\%) were mild, $7(11.9 \%)$ were moderate and $5(8.5 \%)$ were severe (Table 2). Abnormal BCTQ ( $\geq 19)$ was found in $39(14.2 \%)$ participants. There was a positive significant correlation between median nerve CSA and both BCTQ score $(r=0.388, p=<0.001)$ and age $(r=0.346$, $p=<0.001$ ) (Fig. 1). There was also a weak positive correlation between BCTQ score and age $(r=0.158$, $p=0.009$ ). There was significant difference between participants with normal and abnormal median nerve CSA regarding age being older in the abnormal group $(39.25 \pm 11.378 ; \quad 45.17 \pm 9.403) \quad(p=<0.001)$, while there was no difference between both groups regarding gender and occupation $(p=0.718,0.622$, respectively). There were significant differences between means of median nerve CSA and BCTQ $(p=<0.001)$ when compared by $T$ test between normal and abnormal groups (Table 3). It was found that 29(19.1\%) of the medical group (physicians and nurses) and 30(24.6\%)

Table 2 Clinical characteristics of total sample

\begin{tabular}{|c|c|c|c|c|}
\hline & & & \multicolumn{2}{|c|}{$\begin{array}{l}\text { Total examined nerves } \\
\text { (number }=274 \text { ) }\end{array}$} \\
\hline & & & Number & Percent \\
\hline \multicolumn{3}{|c|}{ Median nerve CSA by US $\left(\mathrm{mm}^{2}\right)$ (mean $\left.\pm \mathrm{SD}\right) /$ median } & \multicolumn{2}{|c|}{$(9.08 \pm 2.5) / 9$} \\
\hline \multicolumn{3}{|c|}{$\mathrm{BCTQ}($ mean $\pm \mathrm{SD}) /$ median } & \multicolumn{2}{|c|}{$(19.86 \pm 3.42) / 19$} \\
\hline \multirow{2}{*}{\multicolumn{2}{|c|}{ BCTQ }} & Normal $(\leq 19)$ & 236 & 85.8 \\
\hline & & Abnormal (> 19) & 39 & 14.2 \\
\hline \multirow[t]{5}{*}{ Median nerve CSA by US } & Normal $\left(\leq 10 \mathrm{~mm}^{2}\right)$ & & 215 & 78.5 \\
\hline & \multirow[t]{4}{*}{ Abnormal $\left(>10 \mathrm{~mm}^{2}\right)$} & Mild $\left(>10 m m 2^{2}\right)$ & 47 & 79.7 \\
\hline & & Moderate $\left(>13 \mathrm{~mm}^{2}\right)$ & 7 & 11.9 \\
\hline & & Severe $\left(>15 m m 2^{2}\right)$ & 5 & 8.5 \\
\hline & & Total & 59 & 21.5 \\
\hline
\end{tabular}




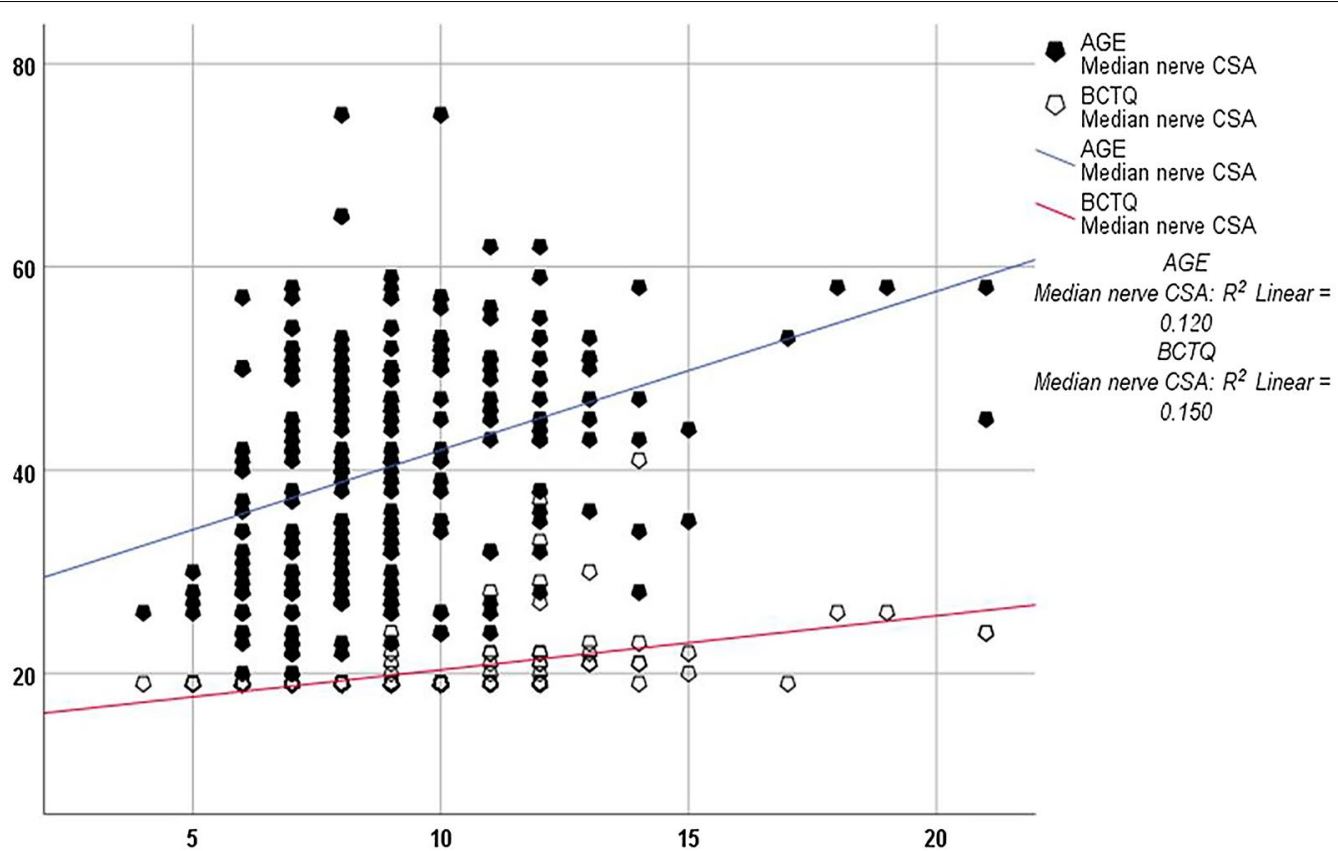

Fig. 1 Correlation between median nerve CSA and both age and BCTQ

Table 3 Comparison between participants with normal and abnormal median nerve CSA

\begin{tabular}{|c|c|c|c|c|c|c|c|}
\hline & & \multicolumn{2}{|l|}{$\begin{array}{l}\text { Normal } \\
(\text { No. }=215)\end{array}$} & \multicolumn{2}{|l|}{$\begin{array}{l}\text { Abnormal } \\
(\text { No. }=59)\end{array}$} & \multicolumn{2}{|c|}{$T$ test/Chi* } \\
\hline & & Mean/Number & SD/percent & Mean/Number & SD/percent & $t / \mathrm{chi}^{*}$ & $p$ \\
\hline \multicolumn{2}{|l|}{ Age } & 39.25 & 11.378 & 45.17 & 9.403 & -4.083 & $<0.001 * *$ \\
\hline \multirow[t]{2}{*}{ Gender } & Male & 56 & 26 & 14 & 23.7 & $0.131^{*}$ & 0.718 \\
\hline & Female & 159 & 74 & 45 & 76.3 & & \\
\hline \multirow[t]{2}{*}{ Occupation } & Medical & 123 & 57.2 & 29 & 49.2 & $1.217^{*}$ & 0.270 \\
\hline & Non-medical & 92 & 42.8 & 30 & 50.8 & & \\
\hline \multicolumn{2}{|c|}{ Median nerve CSA by US ( $\left.\mathrm{mm}^{2}\right)$} & 8.09 & 1.373 & 12.69 & 2.299 & 14.690 & $<0.001 * *$ \\
\hline \multicolumn{2}{|l|}{ BCTQ } & 19.07 & 0.506 & 22.71 & 6.600 & 4.230 & $<0.001^{* *}$ \\
\hline
\end{tabular}

$C S A$ cross sectional area, US ultrasound, BCTQ Boston carpal tunnel questionnaire

${ }^{*}$ Chi test

${ }^{* *} p$ value is significant if $<0.05$

of the non-medical group (secretaries and workers) had abnormal median nerve CSA yet without significant difference $(p=0.325)$. However, there was a significant difference regarding BCTQ (19.27 \pm 1.003 ; $20.59 \pm 4.915, p=0.004)$. Fourteen $(20 \%)$ males and 45(22.1\%) females had abnormal median nerve CSA yet with no significant difference among gender $(p=0.851)$, although there was a significant difference regarding BCTQ score $(19.20 \pm 0.861 ; 20.08 \pm 3.909)$ $(p=0.003)$ (Fig. 2). In the current study, it was found that most of participants with abnormal median nerve
CSA had mild degree (47 nerves), while 7 showed moderate degree and only 5 nerves showed severe degree of abnormal CSA. On comparing clinical characteristics among different degree of abnormal median nerve CSA, it was found that those with severe degree were older with significant difference yet gender, occupation as well as BCTQ showed no significant statistical difference among them (Table 4).

Using linear regression analysis, it was found that age and BCTQ score can be used to predict change in median nerve CSA by $\mathrm{u} / \mathrm{s}$, i.e., increased age by 1 year causes increase in CSA by $0.065 \mathrm{~mm}^{2}$, and any increase 


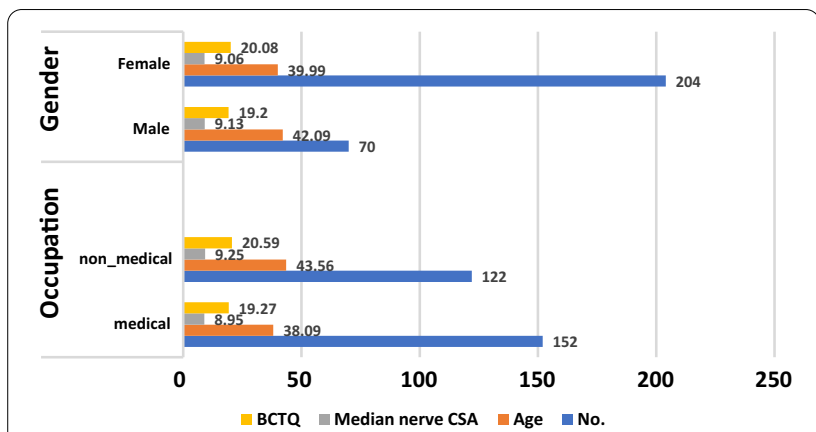

Fig. 2 Comparison between medical versus non-medical and male versus female participants regarding number, age, median nerve CSA and BCTQ

in BCTQ score by one cause increase in CSA by 0.25 $\mathrm{mm}^{2}$ (Table 5).

\section{Discussion}

In this study hospital workers were screened for probable CTS using BCTQ score and median nerve CSA. Ultrasound can be used as a single screening tool for CTS independent from nerve conduction studies [9]. This study showed that $21.5 \%$ of hospital workers have CTS diagnosed by ultrasonography, a study by Castro et al. stated that CTS was diagnosed by ultrasonography in $34 \%$ of their sample [2]. We found that age and BCTQ significantly correlated with CSA and they can also be used as predictors of change in CSA. This finding was compatible with several studies [10-12]. Median nerve CSA was correlated to BCTQ values, previous studies showed positive association between ultrasound and other methods to diagnose CTS including the BCTQ score [13]. Ultrasound detected CTS in $21.5 \%$, while BCTQ detected CTS in $14.2 \%$ indicating the ability of neurosonology to detect subclinical cases. Aktürk et al. stated that the CSA correlates to BCTQ severity and functional disability [14]. Despite higher BCTQ scores among females, there was no significant difference between both sexes regarding CSA. Both sexes, when adjusting the number and workload, they would present almost equally with CTS [15]. Cazares-Manríquez et al. mentioned that CTS is a workrelated disorder almost equally among both sexes despite higher women sensitivity to describe their symptoms [16]. Our results showed that there was significant difference regarding BCTQ between both medical and nonmedical group. The higher score of BCTQ in the medical group could be explained by the number of females in this group which are more sensitive to pain and express

Table 4 Comparison between participants with abnormal median nerve CSA regarding clinical characteristics

\begin{tabular}{|c|c|c|c|c|c|c|c|c|}
\hline & & \multirow{2}{*}{$\begin{array}{l}\text { Mild } \\
\text { (No.=47) } \\
\text { Mean rank/ } \\
\text { number (\%) }\end{array}$} & \multirow{2}{*}{$\begin{array}{l}\text { Moderate } \\
\text { (No.=7) } \\
\text { Mean rank/ } \\
\text { number (\%) }\end{array}$} & \multirow{2}{*}{$\begin{array}{l}\text { Severe } \\
\text { (No.=5) } \\
\text { Mean rank/ } \\
\text { number (\%) }\end{array}$} & \multirow{2}{*}{$\begin{array}{l}\text { Kruskal-Wallis/Chi* } \\
p\end{array}$} & \multirow{2}{*}{$\begin{array}{l}\text { Mild } \\
\text { vs moderate } \\
p\end{array}$} & \multirow{2}{*}{$\begin{array}{l}\text { Mild } \\
\text { vs severe } \\
p\end{array}$} & \multirow{2}{*}{$\begin{array}{l}\text { Moderate vs } \\
\text { severe } \\
p\end{array}$} \\
\hline & & & & & & & & \\
\hline Age & & 29.26 & 22.29 & 47.80 & $0.032^{* *}$ & 0.290 & $0.018^{* *}$ & $0.032^{* *}$ \\
\hline \multirow[t]{2}{*}{ Gender } & Male & $11(23.4 \%)$ & $2(28.6 \%)$ & $1(20 \%)$ & $0.936^{*}$ & & & \\
\hline & Female & $36(76.6 \%)$ & $5(71.4 \%)$ & $4(80.0 \%)$ & & & & \\
\hline \multirow[t]{2}{*}{ Occupation } & Medical & $21(44.7 \%)$ & $5(71.4 \%)$ & $3(60.0 \%)$ & $0.368^{*}$ & & & \\
\hline & Non-medical & $26(55.3 \%)$ & $2(28.6 \%)$ & $2(40.0 \%)$ & & & & \\
\hline \multicolumn{2}{|c|}{ Median nerve CSA by US ( $\mathrm{mm}^{2}$ ) } & 24.00 & 51.00 & 57.00 & $<0.001^{* *}$ & $<0.001^{* *}$ & $<0.001^{* *}$ & $0.003^{* *}$ \\
\hline \multicolumn{2}{|c|}{$\mathrm{BCTQ}$} & 27.79 & 36.57 & 41.60 & 0.103 & & & \\
\hline
\end{tabular}

CSA cross sectional area, US ultrasound, BCTQ Boston carpal tunnel questionnaire

${ }^{*}$ Chi test

${ }^{* *} p$ value is significant if $<0.05$

Table 5 Linear regression analysis

\begin{tabular}{|c|c|c|c|c|c|c|c|}
\hline & Unstar & d coefficients & Standardized & $t$ & Sig. & Collinearit & \\
\hline & $B$ & Std. error & & & & Tolerance & VIF \\
\hline Age & 0.065 & 0.012 & 0.292 & 5.426 & $<0.001^{*}$ & 0.975 & 1.026 \\
\hline BCTQ & 0.249 & 0.039 & 0.341 & 6.339 & $<0.001^{*}$ & 0.975 & 1.026 \\
\hline
\end{tabular}

Dependent variable; Median nerve diameter by US

* $p$ value is significant if $<0.05$ 
more symptoms. CTS is a common condition, resulting not only in impaired quality of life, but also in a significant financial burden to the health system [17]. This study had some limitations as we did not correlate clinical and ultrasound findings with electrophysiological studies and most of the participants were females (74.5\%).

\section{Conclusions}

The prevalence of CTS diagnosed by US among hospital workers was $21.5 \%$. Age and BCTQ were positively correlated to median nerve CSA. CTS can represent a burden among hospital workers so it is recommended to screen for the presence of CTS to lessen such burden. Ultrasound can be used as a noninvasive diagnostic tool for screening for CTS.

\section{Abbreviations}

BCTQ: Boston carpal tunnel questionnaire; CSA: Cross sectional area; CTS: Carpal tunnel syndrome; US: Ultrasound.

\section{Acknowledgements}

Not applicable.

\section{Authors' contributions}

MF: designed and conceptualized the study, drafting the manuscript, performing the Ultrasound. AS: conception of the work and manuscript revision. $I \mathrm{H}$ : acquisition and statistical analysis of data. AA: conception of the work, data collection, drafting the manuscript. All authors have agreed to conditions noted on the Authorship Agreement Form. The content of the manuscript has not been published, or submitted for publication elsewhere. All authors read and approved the final manuscript.

\section{Funding}

No funds were received to fulfill this work.

\section{Availability of data and materials}

The corresponding author takes full responsibility for the data, has full access to all of the data; and has the right to publish any and all data separate and apart from any sponsor.

\section{Declarations}

\section{Ethics approval and consent to participate}

All procedures performed in the study were in accordance with the ethical standards of the faculty of medicine, Ain Shams university research and ethical committee and with the 1964 Helsinki declaration and its later amendments or comparable ethical standards. We obtained approval from research ethics committee no. FWA 000017585. On 15/10/2020. Written informed consent was obtained from participants for participation. We obtained approval from research ethics committee no. FWA 000017585. On 15/10/2020.

\section{Consent for publication}

Not applicable.

\section{Competing interests}

None of the authors has any competing interest.

Received: 10 March 2021 Accepted: 9 September 2021

Published online: 23 September 2021

\section{References}

1. Conlon C, Asch S, Hanson M, Avins A, Levitan B, Roth C, et al. Assessing the value of high-quality care for work-associated carpal tunnel syndrome in a large integrated health care system: study design. Perm J. 2016:20(4):15-220.

2. Castro Ado A, Skare TL, Nassif PA, Sakuma AK, Barros WH. Sonographic diagnosis of carpal tunnel syndrome: a study in 200 hospital workers. Radiol Bras 2015:48(5):287-91.

3. Kim MK, Jeon HJ, Park SH, Park DS, Nam HS. Value of ultrasonography in the diagnosis of carpal tunnel syndrome: correlation with electrophysiological abnormalities and clinical severity. J Korean Neurosurg Soc. 2014:55(2):78-82.

4. Jablecki CK, Andary MT, Flocter MK, Miller RG, Quartly CA, Vennix MJ, et al. Practice parameter: electro-diagnostic studies in carpal tunnel syndrome. Report of the American Association of Electrodiagnostic Medicine, American Academy of Neurology, and the American Academy of Physical Medicine and Rehabilitation. Neurology. 2002;58:1589-92.

5. Billakota S, Hobson-Webb LD. Standard median nerve ultrasound in carpal tunnel syndrome: a retrospective review of 1,021 cases. Clin Neurophysiol Pract. 2017:15(2):188-91.

6. Mondelli M, Filippou G, Gallo A, Frediani B. Diagnostic utility of ultrasonography versus nerve conduction studies in mild carpal tunnel syndrome. Arthritis Rheum. 2008;59(3):357-66.

7. Erensoy $\mathrm{H}$. Translation and validation of the Arabic version of the Boston carpal tunnel syndrome questionnaire. Neurosci J. 2019;24(4):296-301.

8. El Miedany Y. Carpal tunnel syndrome. In: El Miedany Y, editor. Musculoskeletal ultrasonography in rheumatic diseases. Springer, Cham; 2015.

9. McDonagh C, Alexander M, Kane D. The role of ultrasound in the diagnosis and management of carpal tunnel syndrome: a new paradigm. Rheumatology. 2015;54(1):9-19.

10. Bodofsky EB, Campellone JV, Wu KD, Greenberg WM. Age and the severity of carpal tunnel syndrome. Electromyogr Clin Neurophysiol. 2004;44(4):195-9.

11. Kouyoumdjian JA, Zanetta DM, Morita MP. Evaluation of age, body mass index, and wrist index as risk factors for carpal tunnel syndrome severity. Muscle Nerve. 2002;25:93-7.

12. Kouyoumdjian JA. Carpal tunnel syndrome. Age, nerve conduction severity and duration of symp-tomatology. Arq Neuropsiquiatr. 1999:57:382-6.

13. Rao BH, Kutub M, Patil SD. Carpal tunnel syndrome: assessment of correlation between clinical, neurophysiological and ultrasound characteristics. J Sci Soc. 2012;39:124-9.

14. Aktürk S, Büyükavcı R, Ersoy Y. Median nerve ultrasound in carpal tunnel syndrome with normal electrodiagnostic tests. Acta Neurol Belg. 2020;120(1):43-7.

15. McDiarmid M, Oliver M, Ruser J, Gucer P. Male and female rate differences in carpal tunnel syndrome injuries: personal attributes or job tasks? Environ Res. 2000:83(1):23-32.

16. Cazares-Manríquez MA, Wilson CC, Vardasca R, García-Alcaraz JL, OlguínTiznado JE, López-Barreras JA, García-Rivera BR. A review of carpal tunnel syndrome and its association with age, body mass index, cardiovascular risk factors, hand dominance, and sex. Appl Sci. 2020;10(10):3488.

17. Fowler JR, Maltenfort MG, Ilyas AM. Ultrasound as a first-line test in the diagnosis of carpal tunnel syndrome: a cost-effectiveness analysis. Clin Orthop Relat Res. 2013;471:932-7.

\section{Publisher's Note}

Springer Nature remains neutral with regard to jurisdictional claims in published maps and institutional affiliations. 